\title{
Speckle-Free Digital Hologram with Conversion to Off-Axis Horizontal-Parallax-Only Hologram
}

\author{
You Seok Kim and Taegeun $\operatorname{Kim}^{\dagger}$ \\ Department of Optical Engineering, Sejong University, 98 Kunja-dong, Kwangjin-gu, Seoul 143-747, Korea
}

(Received February 28, 2014; Revised manuscript March 24, 2014; Accepted March 24, 2014)

\begin{abstract}
In this paper, we present a speckle-free digital hologram with conversion to an off-axis horizontal-parallax-only (HPO) hologram. First, we record the speckle-free hologram using optical scanning holography. Second, we digitally convert the full-parallax hologram to a horizontal-parallax-only hologram. Third, we convert the horizontal-parallax-only hologram to an off-axis hologram. Finally, we show that the off-axis HPO hologram can be numerically reconstructed in space.
\end{abstract}

Keywords: Holography, Speckle noise, Horizontal-parallax-only hologram

OCIS codes: (090.1995) Digital holography; (090.2870) Holographic display

\section{탈축 수평 시차 홀로그램 변환과 스펙클 잡음 없는 디지털 홀로그램}

\author{
김유석 · 김태근 ${ }^{\dagger}$
}

세종대학교 광전자공학과

(우 143-747 서울시 광진구 군자동

(2014년 2월 28일 받음, 2014년 3월 24일 수정본 받음, 2014년 3월 24일 게재 확정)

본 논문에서는 광 스캐닝 홀로그래피 기술을 이용하여 실제 반사형 물체의 복소 홀로그램을 스펙클 잡음 없이 촬영하고 데이터 양을 줄이면서 동시에 일반적인 진폭 유일 공간 광 변조기를 이용해 광학적인 방법으로 복원할 수 있도록 탈축 수평 시차 홀로그 램으로 변환하였다. 변환된 탈축 수평 시차 홀로그램이 공간상에 복원되어 디스플레이가 될 수 있음을 보이기 위하여 수치적인 방법을 이용하여 홀로그램을 복원하였다.

Keywords: 홀로그래피, 스펙클 잡음, 수평시차 홀로그램

OCIS codes: (090.1995) Digital holography; (090.2870) Holographic display

\section{I. 서 론}

홀로그램을 이용한 3차원 디스플레이는 오랜 역사를 갖고 있다. ${ }^{[1-4]}$ 최근 컴퓨터 기술의 발전으로 디지털 홀로그램을 이용한 3 차원 영상 시스템에 대한 연구가 활발하게 진행되 고 있다. $\left.{ }^{[5,} 6\right]$

디지털 홀로그램을 이용한 3차원 영상 시스템은 3 가지 부 분으로 구성되어 있다. 첫 번째 부분은 실제 물체로부터 홀 로그램을 추출하는 홀로그램 촬영 부분이다. 홀로그램 촬영 부의 경우 기존에 잘 알려진 방법이 있다. ${ }^{[7]}$ 하지만 기존에 제안된 방법의 경우 레이저의 결맞음 특성으로 인하여 스펙 클 잡음에 심각하게 오염되어 있다. ${ }^{[7,8]}$ 최근 이 단점을 극복 하고 실제 물체의 홀로그램을 스펙클 잡음 없이 촬영한 연구
결과가 보고되었다. ${ }^{[9]}$

디지털 홀로그램을 이용한 3차원 영상 시스템의 두 번째 부분은 홀로그램 정보를 전송 및 복원에 적합한 형태로 변환 하는 디지털 신호처리부분이다. 디지털 홀로그램을 이용한 3 차원 영상 시스템의 실용화에 있어 걸림돌 중 하나는 홀로그 램을 이용한 3 차원 영상 시스템에 요구되는 데이터 양이 방 대하다는 것이다. 이 문제점을 극복하기 위해서는 요구되는 데이터 양을 줄이는 신호처리가 필요하다.

디지털 홀로그램을 이용한 3차원 영상 시스템의 세 번째 부분은 홀로그램 복원 부분이다. 이 부분은 홀로그램 데이터 를 광학적인 방법으로 공간상에 복원하여 3차원 디스플레이 를 수행하는 영역이다. 일반적으로 복원 부분에서는 공간 광 변조기를 이용하여 빛의 분포를 홀로그램과 같이 변조하여

\footnotetext{
${ }^{\dagger}$ E-mail: takim@sejong.ac.kr

Color versions of one or more of the figures in this paper are available online.
} 
물체의 3차원 영상을 공간상에 복원하여 디스플레이를 실행 한다. 여기서, 일반적인 공간 광 변조기는 빛의 진폭 또는 위 상만을 변조한다. 이 때문에 공간 광 변조기를 이용한 광학 적인 복원의 경우 복소 홀로그램을 완벽하게 변조하지 못한 다는 문제점이 있다. 이 문제점을 해결하기 위한 방법 중 하 나로 복소 홀로그램을 진폭 유일의 탈축 홀로그램으로 변환 하는 방법이 제안되었다. ${ }^{[10]}$

본 연구에서는 광 스캐닝 홀로그램을 이용하여 실제 물체 의 홀로그램 정보를 배경 잡음, 쌍 영상 잡음, 스펙클 잡음 없이 촬영하고 이를 수치적으로 처리하여 요구되는 데이터 양을 줄이면서 동시에 진폭 유일 공간 광 변조기를 이용해 변조 가능한 형태인 탈축 수평 시차 홀로그램으로 변환하고, 이를 수치적 방법으로 복원하여 공간상에 3 차원 복원이 가 능함을 보였다.

\section{II. 광 스캐닝 홀로그래피}

그림 1 은 실제 물체의 홀로그램을 스펙클 잡음 없이 촬영 할 수 있는 광 스캐닝 홀로그래피의 구성도이다. 광 스캐닝 홀로그래피는 스캐닝 거울을 이용한 2차원 스캔으로 실제 물체의 홀로그램 정보를 촬영할 수 있는 시스템으로 기존 연 구에서 제안되었다. ${ }^{[9]}$ 본 논문에서는 광 스캐닝 홀로그래피 에 대하여 간단하게 소개하고자 한다. 광 스캐닝 홀로그래피 는 두 개의 빔 분할기(BS1, 2)와 두 개의 거울(M1, 2)로 구 성된 간섭계 부분과 빛의 세기 형태의 신호를 전기 신호형태 로 변환한 뒤 신호처리를 진행하는 전기 신호처리 부분으로 나눌 수 있다. 레이저에서 나온 빛은 빔 분할기(BS1)에서 두 개의 경로로 나뉘어진다. 나뉘어진 빛은 음향 광 변조기 (AOM1, 2)를 통과하면서 특정 주파수로 변조된다. 이 때 음 향 광 변조기의 변조 주파수는 각각 $\Omega$ 와 $\Omega+\Delta \Omega$ 로 설정해준 다. 음향 광 변조기를 통과한 빛은 빔 확대기 $(\mathrm{BE} 1,2)$ 를 통과 하면서 크기가 확장되고 두 번째 빔 분할기(BS2)에서 서로 합쳐서 간섭을 일으키게 된다. 이 때 한 쪽 경로에만 렌즈 (L1)을 두어 구면파와 평면파가 간섭되도록 해준다. 구면파 와 평면파가 간섭되면 특이한 간섭무늬가 나타나게 되는데 이를 프레넬 윤대판이라고 부른다. 프레넬 윤대판 형태의 빛 을 스캐닝 거울을 이용하여 실제 물체를 스캔하고 반사된 빛

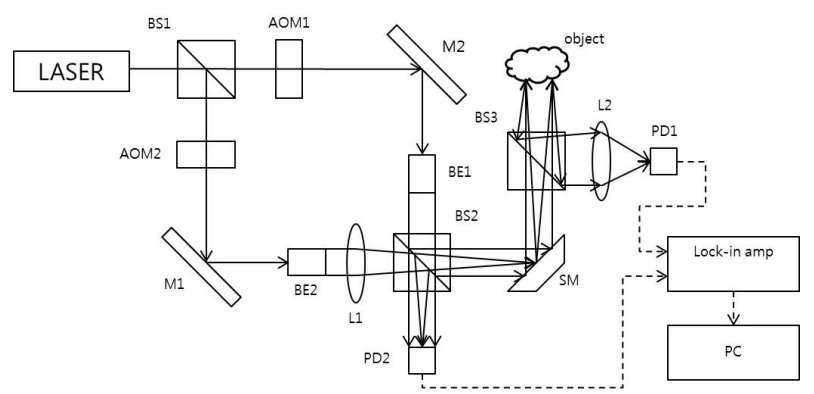

FIG. 1. Optical scanning holography (BS: beam splitter, AOM: Acousto optic modulator, M: mirror, BE: beam expander, SM: Scanning mirror, PD: photo detector, L: lens, PC: personal computer).
을 렌즈(L2)로 집광한다. 집광된 빛은 광 검출기(PD1)를 이 용하여 전기 신호 형태로 변환된 후 lock-in 증폭기를 통과하 여 컴퓨터( $\mathrm{PC})$ 에 저장되게 된다. 수치적인 방법을 이용하여 저장된 신호를 합성하면 복소 홀로그램을 얻을 수 있다. 홀 로그램을 얻는 과정을 수식으로 표현하면 식 (1)과 같이 나 타낼 수 있다. ${ }^{[10]}$

$$
H(x, y)=|H| \exp (j \angle H)=\int I_{o}(x, y, z) \otimes \frac{j}{\lambda z} \exp \left\{j \frac{\pi}{\lambda z}\left(x^{2}+y^{2}\right)\right\} d z
$$

식 (1)에서 $I_{o}(x, y, z)$ 는 실제 물체의 세기를 나타내고 $z$ 는 물체의 깊이를 나타낸다. $\lambda$ 는 레이저의 파장을 나타낸다. 이 렇게 얻은 복소 홀로그램의 경우 수평 방향에 대한 시차 정 보와 수직 방향에 대한 시차 정보를 모두 가지고 있는 전 시 차(full parallax) 홀로그램이다. 전 시차 홀로그램의 경우 데 이터 양이 많다는 문제점을 가지고 있다. 다음 장에서 이를 극복하기 위해 전 시차 홀로그램을 수평 시차 홀로그램으로 변환한다.

\section{III. 수평 시차 홀로그램 변환}

홀로그램을 이용한 3 차원 영상 시스템의 실용화에 있어 난 제 중 하나는 요구되는 데이터 양이 방대하다는 것이다. 사 람의 시각인지가 수직 방향보다 수평 방향에 좀 더 민감하다 는 점에 착안하여 홀로그램의 데이터 양을 줄일 수 있는 방 법 중 하나로 수평 시차(horizontal-parallax-only) 홀로그램이 제안되었다. ${ }^{[1]}$ 수평 시차 홀로그램은 수평 방향에 대한 시차 정보만을 가지고 있어 요구되는 데이터 양을 줄 일 수 있다 는 장점이 있다. 본 논문에서는 2장에서 획득한 실제 반사형 물체의 전 시차 홀로그램을 수치적인 방법으로 수평 시차 홀 로그램으로 변환한다. ${ }^{[1]}$

그림 2는 전 시차 홀로그램을 수평 시차 홀로그램으로 변 환하는 수치적인 방법의 흐름도를 나타내고 있다. 먼저 수직 방향에 대하여 주파수 축에서 가우시안 저역 통과 필터를 적 용해준다. 가우시안 저역 통과 필터는 식 (2)와 같이 나타낼 수 있다. 식 (2)에서 $N A_{g}$ 는 가우시안 저역 통과 필터의 컷오프 주파수를 나타낸다. $k_{x}$ 와 $k_{y}$ 는 각각 수평 방향의 주 파수 축과 수직 방향의 주파수 축을 나타낸다. 가우시안 저 역 통과 필터를 적용하였을 경우 수평 시차 홀로그램을 얻을 수 있지만 수직 방향으로 곡률이 존재하게 된다.

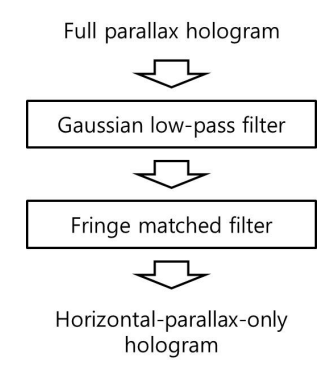

FIG. 2. Flow chart of conversion to a horizontal-parallax-only hologram. 


$$
G_{\text {low-pass }}\left(k_{x}, k_{y}\right)=\exp \left[-\frac{1}{4 \pi}\left(\frac{\lambda}{N A_{g}}\right)^{2} k_{y}^{2}\right]
$$

이 곡률의 경우 홀로그램을 복원할 때 왜곡으로 작용할 수 있어 보상이 필요하다. 곡률을 보상하기 위하여 프린지 매치 필터를 가우시안 저역 통과 필터와 마찬가지로 주파수 축에 서 수직 방향으로 적용한다. 프린지 매치 필터는 식 (3)과 같이 나타낼 수 있다. 식 (3)의 $z_{0}$ 는 물체의 깊이 위치를 나타낸다.

$$
F_{f m}\left(k_{x}, k_{y}\right)=\exp \left[-j \frac{\lambda z_{0}}{4 \pi} k_{y}^{2}\right]
$$

전 시차 홀로그램을 수평 시차 홀로그램으로 변환하기 위 하여 가우시안 저역 통과 필터뿐 아니라 위상 변화가 없는 모든 종류의 저역 통과 필터를 사용할 수 있다. 하지만 사각 필터와 같이 커팅-엣지가 급격한 필터를 사용할 경우 리플과 같은 수치적 결함이 발생할 수 있다. 또한 광 스캐닝 홀로그 래피 스캔 빔이 가우시안 프로파일을 가지고 있어 그에 부합 하는 가우시안 프로파일을 형성하기 위해 가우시안 저역 통 과 필터를 사용하였다.

이렇게 변환 된 수평 시차 홀로그램은 복소 홀로그램으로 수치적인 방법으로 복원할 경우 배경 잡음과 쌍 영상 잡음 없이 홀로그램을 복원할 수 있다. 하지만 공간 광 변조기를 이용하여 광학적인 방법으로 홀로그램을 복원할 경우 공간 광 변조기가 복소 데이터를 표현할 수 없기 때문에 쌍 영상 잡음과 배경 잡음 없이 홀로그램을 복원할 수 없다. 쌍 영상 잡음과 배경 잡음 때문에 복원된 홀로그램이 깨끗하지 않다. 이 문제점을 해결하기 위하여 복소 홀로그램에 수치적인 방 법을 이용하여 공간 캐리어를 인가해 배경 잡음과 쌍 영상 잡음의 영향을 받지 않는 탈축 홀로그램으로 변환하는 방법 이 제안되었다. ${ }^{[10]}$ 다음 장에서 탈축 홀로그램으로 변환하는 방법에 대하여 소개하고자 한다.

\section{IV. 탈축 홀로그램 변환}

홀로그램을 광학적인 방법으로 공간상에 복원하여 디스플 레이 하기 위해서는 빛의 공간적 분포를 공간 광 변조기를
이용하여 홀로그램 패턴으로 변조해 주어야 한다. 그러나, 일반적인 공간 광 변조기는 빛의 진폭 또는 위상만을 변조할 수 있다. 본 장에서는, 빛의 진폭만을 변조할 수 있는 진폭 유일 공간 광 변조기를 이용하여 홀로그램을 광학적으로 복 원하기 위하여, 수치적인 방법으로 2장에서 얻은 수평 시차 홀로그램에 공간 캐리어를 인가하는 방식으로 탈축 홀로그 램으로 변환한다. 다음은 탈축 홀로그램으로 변환하는 과정 에 대한 설명이다.

$$
\begin{aligned}
& H_{\text {off-coxis }}^{\text {complex }}(x, y)=|H| \exp (j \angle H) \times \exp \left(j \frac{2 \pi \sin \theta}{\lambda} x\right) \\
& =|H| \exp \left[j\left(\angle H+\frac{2 \pi \sin \theta}{\lambda} x\right)\right]
\end{aligned}
$$

식 (4)는 복소 홀로그램에 공간 캐리어를 인가하여 탈축 홀로그램으로 변환하는 과정을 나타낸 수식이다. $\exp \left(j \frac{2 \pi \sin \theta}{\lambda} x\right)$ 는 인가된 공간 주파수를 나타내며 $\theta$ 는 기준광의 광 축과 물체광의 광 축의 사이각을 나타난다. 공간 광 변조기를 이 용하여 변환된 탈축 홀로그램을 광학적인 방법으로 복원할 경우 입사시켜준 참조광의 광 축과 $\theta$ 만큼 공간적으로 분리 되어, 배경 잡음, 쌍 영상 잡음이 공간적으로 분리되어 잡음 없이 홀로그램이 공간 상에 복원된다. 식 (4)와 같이 수치적 으로 변환된 탈축 홀로그램의 실수 부분을 추출한 뒤 DC 바 이어스를 인가하여 최종적으로 진폭 유일 공간 광 변조기에 서 표현할 수 있는 탈축 홀로그램으로 변환한다.

\section{V. 실험결과}

본 연구에서는 광 스캐닝 홀로그래피를 이용하여 $3 \mathrm{~mm} \times 3$ $\mathrm{mm} \times 3 \mathrm{~mm}$ 의 주사위의 홀로그램을 촬영하였다. 실험에 사용 한 레이저는 파장이 $532 \mathrm{~nm}$ 인 Nd-YAG 레이저를 사용하였 고 두 개의 음향 광 변조기의 변조 주파수는 각각 $40 \mathrm{MHz}$ 와 $40.01 \mathrm{MHz}$ 로 설정하였다. 구면파를 만들어주는 렌즈(L1)는 초점거리가 $500 \mathrm{~mm}$ 인 렌즈를 사용하였다. 탈축 홀로그램 변 환을 위한 공간 주파수의 $\theta$ 는 $1.74^{\circ}$ 로 해주었다.

그림 3(a)와 그림 3(b)는 광 스캐닝 홀로그래피로 촬영한 복소 홀로그램의 세기 이미지와 위상 이미지를 보여준다. 광 스캐닝 홀로그래피의 경우 반사된 빛을 렌즈로 집광하는 공

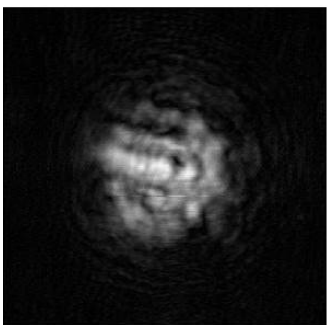

(a)

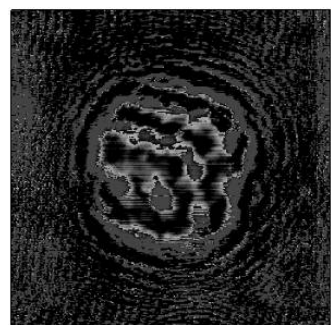

(b)

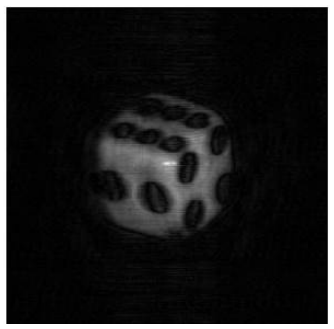

(c)

FIG. 3. (a) Amplitude of the complex hologram (b) Phase of the complex hologram (c) Numerical reconstruction of the complex hologram. 
간 통합 처리과정을 이용하여 스펙클 잡음 없이 홀로그램을 촬영할 수 있다. 그림 3(b)를 보면 스펙클 잡음 없이 홀로그 램을 촬영하였기 때문에 프린지 패턴을 관찰할 수 있다. 그 림 3(b)를 보면 수평 방향과 수직 방향 모두 프린지 패턴이 존재한다는 것을 알 수 있다. 즉 수평 방향과 수직 방향의 시차 정보를 모두 가지고 있는 전 시차 홀로그램임을 알 수 있다. 그림 3(c)는 광 스캐닝 홀로그래피를 이용하여 촬영한 홀로그램을 수치적으로 복원한 결과이다. 그림 3(c)를 보면 스펙클 잡음 없이 홀로그램이 깨끗하게 복원되는 것을 확인 할 수 있다.

그림 4(a)는 앞서 소개한 디지털 연산 방법을 이용하여 탈 축 수평 시차 홀로그램으로 변환한 복소 홀로그램의 실수 부 분을 나타낸다. 그림4(b)는 그림4(a)의 일부 영역을 확대한 그림이다. 그림4(b)를 보면 세로 방향으로 격자 무늬가 보이 는 것을 확인할 수 있다. 이 격자 무늬가 복원된 홀로그램을 배경 잡음과 쌍 영상 잡음으로부터 공간적으로 분리하는 역 할을 한다.

그림 5 는 그림 4 의 변환 된 탈축 수평 시차 홀로그램의 실 수 부분만을 추출하여 DC 바이어스를 인가한 후 수치적으로 복원한 결과이다. 그림 5 를 보면 세 영역에서 이미지가 존재 하는 것을 알 수 있다. 그림 5 의 중앙은 배경 잡음을 나타내 고 배경 잡음을 기준으로 왼쪽은 복원된 홀로그램, 오른쪽은 쌍 영상 잡음을 나타낸다. 이 결과를 통해서 변환된 탈축 수 평 시차 홀로그램이 배경 잡음과 쌍 영상 잡음의 영향을 받 지 않고 공간적으로 분리되어 복원된다는 것을 알 수 있다. 또한 복원된 홀로그램을 보면 수평 시차 홀로그램으로 변환

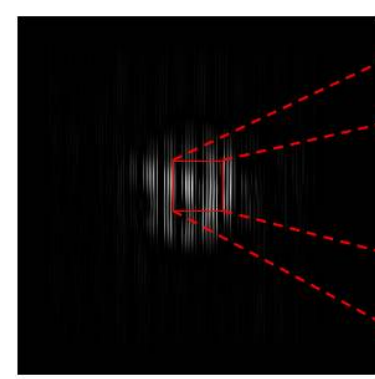

(a)

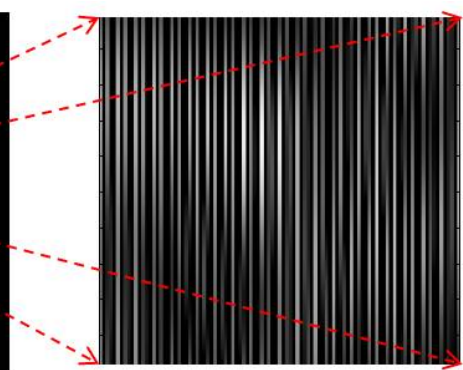

(b)
FIG. 4. (a) Real part of the horizontal-parallax only (HPO) off-axis hologram (b) Enlarged image within the red box of (a).

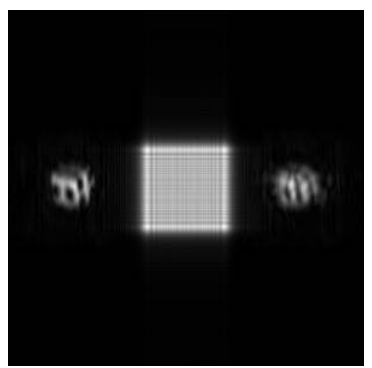

FIG. 5. Numerical reconstruction of the HPO off-axis hologram.
되었기 때문에 수직 방향으로는 시차정보를 가지고 있지 않 아 초점을 맺지 못하고 뿌옇게 흐려지는 것을 확인할 수 있 다. 수직 방향으로 뿌옇게 흐려지는 것은 그림 3(c)과 비교하 면 좀 더 뚜렷하게 확인할 수 있다. 이를 통하여 본 연구에 서 목표로 하였던 수평 시차 탈축 홀로그램으로 변환이 잘 되었다는 것을 확인할 수 있었다.

\section{VI. 결 론}

본 연구에서는 광 스캐닝 홀로그래피를 이용하여 반사형 물체의 복소 홀로그램을 스펙클 잡음 없이 추출하는데 성공 하였고 추출한 복소 홀로그램을 탈축 수평 시차 홀로그램으 로 변환하는데 성공하였다. 또한 변환된 탈축 수평 시차 홀 로그램을 수치적인 복원 방법을 이용하여 배경 잡음과 쌍 영 상 잡음의 영향을 받지 않고 공간적으로 분리되어 복원됨을 확인하였다. 본 연구를 통하여 광 스캐닝 홀로그래피 기반의 디지털 홀로그램을 이용한 3 차원 영상 시스템의 구현 가능 함을 보였다.

본 연구에서는 최초로 실제 반사형 물체의 복소 홀로그램 을 추출하고 탈축 수평 시차 홀로그램으로 변환하는 홀로그 램 3차원 영상 시스템을 시연하였고, 공간상에 복원됨을 수 치적 방법으로 검증하였다. 향후 홀로그램을 광학적으로 복 원하여 광 스캐닝 홀로그래피 기반의 디지털 홀로그램을 이 용한 3차원 영상 시스템을 구성할 계획이다.

\section{감사의 글}

본 연구는 Giga Korea 사업의 디지털 홀로그래픽 테이블 탑형 단말 기술 개발 사업[GK13D0100]의 지원에 의해 수행 되었습니다.

\section{References}

1. C. Burckhardt and L. Enloe, "Television transmission of holograms with reduced resolution requirements on the camera tube," Bell Syst. Tech. Jour 45, 1529-1535 (1969).

2. J. Berrang, "Television transmission of holograms using a narrow-band video signal," Bell Syst. Tech. J. 49, 879-887 (1970).

3. T. C. Poon, B. W. Schilling, M. H. Wu, K. Shinoda, and Y. Suzuki, "Real-time two-dimensional holographic imaging by using an electron-beam-addressed spatial light modulator," Opt. Lett. 18, 63-65 (1993).

4. T.-C. Poon, "Optical scanning holography - A review of recent progress," J. Opt. Soc. Korea 13, 406-415 (2009).

5. P. St. Hilaire, S. A. Benton, and M. Lucente, "Synthetic aperture holography: A novel approach to three-dimensional displays," J. Opt. Soc. Am. A 9, 1969 (1992).

6. M. Stanley, "3D electronic holography display system using a 100-megapixel spatial light modulator," Proc. SPIE 5249, 
297-308 (2004).

7. I. Yamaguchi and T. Zhang, "Phase-shifting digital holography," Opt. Lett. 22, 1268 (1997).

8. O. Matoba, T. J. Naughton, Y. Frauel, N. Bertaux, and B. Javidi, "Real-time three-dimensional object reconstruction by use of a phase-encoded digital hologram," Appl. Opt. 41, 6187-6192 (2002).

9. Y. Kim, T. Kim, S. Woo, and H. Kang, "Speckle-free digital holographic recording of a diffusely reflecting object," Opt.
Express 21, 8183-8189 (2013).

10. Y.-S. Kim, T.-G. Kim, and J.-T. Kim, "Three-dimensional holographic display with twin image noise rejection using off-axis hologram converting," Korean J. Opt. Photon. (Hankook Kwanghak Hoeji) 20, 328-333 (2009).

11. T. Kim, Y. S. Kim, W. S. Kim, and T. Poon, "Algorithm for converting full-parallax holograms to horizontal-parallaxonly holograms," Opt. Lett. 34, 1231-1233 (2009). 